\title{
Language Design and Communicative Competence: The Minimalist Perspective
}

\author{
Elliot Murphy ${ }^{1}$
}

1. Division of Psychology and Language Sciences, University College London

(1)

Abstract: In the Minimalist Program, the place of linguistic communication in language evolution and design is clear: It is assumed to be secondary to internalisation. I will defend this position against its critics, and maintain that natural selection played a more crucial role in selecting features of externalization and communication than in developing the computational system of language, following some core insights of minimalism. Alongside this computational system, human language exhibits ostensive-inferential communication via open-ended combinatorial productivity, and I will explore how this system is compatible with - and does not preclude - a minimalist model of the language system.

Keywords: Code model, speech control, recursion, intersubjectivity, primate cognition

'For in spite of language, in spite of intelligence and intuition and sympathy, one can never really communicate anything to anybody.' - Aldous Huxley (1931)

Natural language exhibits a range of features which pose difficulties for evolutionary accounts which hold that it primarily evolved to serve a communicative function. The property of discrete infinity, for example, has a wide range of cognitive functions (Hauser and Watumull, 2017), making it appear more plausible that it was selected for aiding recursive forms of cognition, or mathematics, or morality. Language differs from animal systems of communication in that it is not stimulus-driven, nor does it have a specialised function like 
alarm calls or seduction songs. It is a major claim of contemporary minimalist linguistics that the core features of language (discrete infinity and semanticity) are not found in other known communication systems, and as such it is implausible to claim that language evolved for communication. Recursive embedding and dislocation in fact hinder communication (Pietroski and Crain, 2005), and there appear to be no communicative advantages to successive-cyclic movement, the conservativity of quantifiers, and numerous other core properties of the syntaxsemantics interface (Boeckx, 2003). The language faculty is itself underspecified, being able to be realised morpho-phonologically and syntactically in a variety of ways, lacking a stable state of the kind needed to maximise communicative efficiency. In addition - and perhaps most importantly - investigating the role of language in communication tells us nothing about the design of the language system itself; the major goal in contemporary minimalism (Chomsky, 2001). Even a cursory review of the minimalist literature reveals that the structure and design of language is assumed to be optimised for cognition, not externalisation, and this is consequently where the bulk of research has been focused; namely, into rules governing morpho-phonology, morpho-syntax, agreement, labeling, transfer, phases, the feature types manipulated by syntax, and economy principles like Last Resort (Adger, 2019). The general trend is to focus on the formal structure of language, rather that its range of potential functions. Minimalism and 'internalism' (which, in philosophy of biology, stresses the importance of structural complexity over external shaping effects; Amundson, 2006; McGhee, 1998) is also the standard position in physics: the solar system has no 'function', but it does have an internal structure, dictated by natural law.

None of this is to deny that language is used for communication. Rather, it is to deny that its design features are primarily geared towards communication. As Fodor and Pylyshyn (2015) explore, thoughts and sentences share identical structural organisation (see also Pietroski, 2018). As Jackendoff (1990: p. 27) claimed shortly before evolutionary linguistics became a 
major topic of concern, 'syntax presumably evolved as a means to express conceptual structure, so it is natural to expect that some of the structural properties of concepts would be mirrored in the organization of syntax'. In addition, none of this is to deny the gradual impact of communicative factors on syntax, either: Consider, for instance, how Kayne (1994) initially provided a UG-based parametric account for why rightward movement is generally restricted cross-linguistically, only for Ackema and Neeleman (2002) to account for this through invoking increased parsing (and, hence, communicative) difficulties. Moreover, it is not strictly the case that minimalists have a precise conception of communication per se; rather, they have a conception of the language faculty's relation to communication.

The communication systems of nonhuman primates (prosimians, monkeys and apes) appear to have a fully specified semantics related to basic, non-complex concepts. Reboul (2015) presents convincing arguments against the common idea that human language is a 'communication system'; indeed, 'communication' is not a natural class and so any putative human communication system cannot have been subject to the laws of evolution, and is rather a collection of distinct processes like intention, reference, imitation, etc. In fact, the term 'communication' will always need considerable unpacking, no matter what theoretical context it appears in. As Chomsky (2018: p. 34) notes, 'probably 99\% of our use of language' involves 'talking to ourselves, something that we do constantly, night and day, and can only be prevented by a dedicated act of will'. Chomsky notes that while internal speech is 'conscious' in its phonology, everything else about it is unconscious (syntax and semantics). Chomsky provides no direct empirical support for this 'probably 99\%' claim, although it is difficult to think of ways to conduct a controlled investigation of language use once one considers the range of cognitive functions narrow syntax might be contributing to (Hauser and Watumull, 2017). Dor (2017: p. 44) even argues that the evolution of language aided our ability to lie possibly more than it aided our ability to communicate: 'We evolved for lying, and because of 
lying, just as much as we evolved for and because of honest communication'. He adds: 'Language would be much simpler had it evolved just for honest communication, and we would be much less imaginative, suspicious and inquisitive, and emotionally-controlled. We would probably have very little symbolic culture, no myths, no propaganda, and we would also probably insult each other much more often' (Dor, 2017: p. 57).

The human conceptual system is also uniquely rich, with 3-year-olds reaching 300 words, the very limit that adult non-humans have acquired after intensive training (Anderson, 2004). Numerous monkey species also produce call combinations which convey complex meanings distinct from the atomic calls, but do this in a highly constrained and non-cyclic fashion (Zuberbühler, 2012). Monkey alarm calls in particular appear to be homologous to spontaneous human emotional vocalisations, given their common neural organisation (Owren et al., 2010, 2011). Bottlenose dolphins demonstrate 'a capability for reasoning about higher order relations through the spontaneous combination or concatenation of previously generalized concepts' (Herman et al., 2008: p. 139). A syntactic labeling operation (Shim, 2018) appears to be absent from all of these computations. Nevertheless, a basic syntax with compositional semantics has been argued for in the discrete vocal system of a social passerine, the pied babbler (Turdoides bicolor) (Engesser et al., 2016), and it is likely that limited forms of compositionality ranging over a highly constrained set of calls/gestures exist in other birds and primates.

Though clearly lacking in cyclicity, the evolution of rhythm can be explored through examining the drumming behaviour of Fongoli chimpanzees. These apes crack a baobab fruit (Strydinos spp) in a particular rhythm, and as Meguerditchian et al. (2017) review the sequences appear to be composed of repetitive power beats, or sequences of 1 power beat +1 soft beat, or 1 power beat +2 soft beats. Interestingly, this appears to map onto the basic syntax of monkey calls (Murphy, 2016b), such that calls can be isolated or delivered with a smaller 
morphological element, similar to 1 power beat +1 soft beat structures. A more complex rhythmic pattern is not found amongst these chimpanzees.

But while animal communication systems may or may not be discrete and compositional, animal conceptual systems certainly are. Nonhumans can grasp colour, material, location and number concepts and map these onto novel situations and objects (Shettleworth, 2009). They can also recombine learned concepts productively through using reasoning by exclusion (Aust et al., 2008) or transitive inference (Paz-y-Miño et al., 2004) to infer concepts they have no perceptual basis for. Likewise, while baboon calls and their associated meanings may be simple, baboon cognition is far from rudimentary, exhibiting hierarchical social structures, semantic combinatorics and a rich pragmatic system (Fitch, 2017). Koko, a western lowland gorilla, exhibited the ability to master over 1000 gestural signs, even combining discrete signs to refer a new object which corresponded to the intersection of the meaning of two signs, referring to a ring as a 'finger bracelet' (Patterson and Linden, 1981). Yet no ape communication researchers have so far shown that nonhuman species can use a hierarchical reassembly process to imitate such gestural or vocal forms, suggesting that the gestural signs used by apes are implemented simply through more basic forms of imitation. Primate calls also typically exhibit an audience effect, being used on the presence of conspecifics, whereas human language is often externalised in the absence of any audience. Meanwhile, human syntax is deployed in a range of novel ways which aids planning, interpretation and memory - and when it is used to communicate, it is often done to manipulate and influence the mindset of others to one's own advantage (see Reboul, 2015). 
What of other, closely connected linguistic notions? Terrace, reviewing decades of ape communication studies, claims that there is '[n]o evidence that apes used any of the symbols they learned to refer to objects or events, or that those symbols had any function other than to request food or drink' (2005: p. 101). What ethologists define as the eagle call may not, in fact, refer to eagles: Animal communication 'units aren't designed to refer, they're designed to get other animals to do things' (Bickerton, 2009: p. 12). Bees and ants also display the capacity for signal displacement (e.g. the waggle dance of bees), but these signals are thoroughly hardwired and genetically determined, whereas humans can achieve signal displacement simply through conventional learning (Aboitiz, 2017: p. 18-22). Informally speaking, it has been well established by ethologists that animals do not have names for things, but what has not been recognised by many language scientists is that neither do humans: Internalist studies in philosophy of language show that lexical items are highly intricate and conceptually independent of the entities posited by physical theory (Chomsky, 2000, 2018; Hinzen, 2006, 2007). Contrary to externalists like Putnam (1975) and Burge (1979), water does not 'equal' $\mathrm{H}_{2} \mathrm{O}$ partly because '[e]ntities in a domain of the mind do not symbolize other elements in that domain: they are the elements' (Bouchard, 2013: p. 44). Indeed, 'the belief in the existence of definitions is really utopian' (Hornstein, 1984: p. 132).

There are also reasons to believe that sensorimotor processes shared across a variety of vertebrates could underlie language-universal acoustic patterns in humans, supporting the minimalist assumption that components of externalisation should not be the focus of speciesspecific investigations into language. Particular focus should be placed on terrestrial vertebrates, or tetrapods (nonavian reptiles, mammals, birds, amphibians), with whom we share a substantial proportion of our hearing and vocal production machinery. As Fitch (2018: p. 263) summarises: '50 years of comparative speech research reveals a broadly shared set of perceptual mechanisms that, although potentially evolved for conspecific voice perception in 
amniotes, are in no sense unique to human speech'. Fitch adds that certain 'phenomena such as categorical perception may represent domain-general processing mechanisms, whereas others such as vocal tract normalization may be specific to vocal sounds' (Ibid).

Indeed, upon immediate inspection, there seems nothing directly comparable to natural language syntax in the rest of the animal kingdom, posing a problem for the comparative language sciences. For all the work of comparative ethologists and linguists, there may be 'not much to compare' (Bolhuis et al., 2014). However, there are certain capacities that interface with language which we likely share with a range of species. Our human-specific powers of imitation most probably explain our wide vocabularies, for instance. With great imitation power comes the possibility to acquire a large lexicon. Newborn infants only 42 minutes old have the ability to replicate adult gestures on mouth-opening, tongue-protrusion and lipprotrusion (Meltzoff and Moore, 1997). The evolution of human-specific imitation abilities may go some way to explain the lack of a substantial vocabulary in closely related species.

Recent work has begun to explore this issue. Hobaiter and Byrne (2017) systematised aspects of ape gestures (e.g. rhythmic repetition, contact with recipient, movement) and showed that, taking into account all of these gestural features readily used by apes, there is a potential repertoire of over 1000 gestures given all possible combinations. Yet, in reality apes only use just over a tenth of all possible gestures, pointing not to physical (motor) limitations, but to the absence of mental combinatorial flexibility, of the kind that human language readily delivers. Only in human language do we see such an impressively large store of units to manipulate on the fly, and while categories such as noun and adjective may not be innate (since these differ cross-linguistically), the capacity to categorise in such a way is likely human-specific. Even in the case of complex feeding skills exhibited by gorillas, it is not at all clear that their powers of imitation are sufficient for learning, since the young appear to look not at the complex motor actions when they are learning, but rather the food itself (Corp and Byrne, 2002), which 
suggests that other learning strategies (e.g. trial and error) besides imitation might be responsible (or at least contribute to) their knowledge. Arbib (2012: p. 191) summarises related research: 'Monkeys have little or no capacity for imitation beyond observational priming and macaques had their common ancestor with humans some 25 million years ago. Apes have an ability for imitation by behavior parsing and had their last common ancestor with humans some 5 to 7 million years ago'. Arbib concludes from this that 'our evolutionary path took us through the emergence of imitation by behavior parsing before 7 million years ago, with complex imitation being an emergent [feature] of hominid evolution'.

Along with imitation, there are a host of physiological traits which appear to aid various linguistic processes. For instance, Kalashnikova et al. (2017) show that infant-directed speech (IDS) exhibits acoustically exaggerated vowels which are not the result of adjustments to tongue or lip movements, but rather result from a shortened vocal tract (relative to other great apes) thanks to a raised larynx. This supposedly occurs because adults unconsciously try and appear smaller and less threatening to infants. Kalashnikova et al. (2017) speculate: 'This adjustment in IDS may be a vestige of early mother-infant interactions, which had as its primary purpose the transmission of non-aggressiveness and/or a primitive manifestation of prelinguistic vocal social convergence of the mother to her infant'. When human language emerged, a secondary purpose for IDS did too: 'facilitating language acquisition via the serendipitously exaggerated vowels’.

With respect to the evolution of this categorisation capacity, in terms of its implementation it likely evolved from an expanded procedural memory system involved in statistical-sequential analysis (Wijnen, 2013). But what of its implementation within a given 'language game', in the Wittgensteinian sense? Steels (1995) presented the 'naming game' as a possible insight into how agreed upon and popular words first emerged. In this game, a population of agents are tasked with coming up with names for other agents. When a group of 
agents have no name for a given nameless agent, one of them is either forced to randomly generate a word, or choose a name from its existing mental store of names (with the probability being proportional to the previous success of the name being used in the community). If the agents then agree on this classification, then the success of the given name is increased through positive feedback. This process helps contribute to the formation of lexicons without any central control, even if it is says nothing about the origins of lexical atoms themselves (i.e. their neural and genetic basis).

Natural selection likely played a more crucial role in selecting features of externalization than in developing the computational system of language. For instance, manufacturing and tool use may have had selective advantage insofar as communicative burdens were relieved from the hands and transferred to the face. Communication is plainly not an ability unique to humans, and is something even bacteria seem to do (via quorum sensing; Williams et al., 2007). Symbiotic relationships can even result in cross-species communication, such as when the honeyguide bird leads honey badgers to bee nests via a specific sound, at which point the badger breaks the nest and both species are able to benefit from the nutrition. Elephants communicate through infrasounds that the human ear cannot pick up, while electric fish communicate through generating specific currents that only they can produce and sense. Human language seems unique, as we will see, in that it exhibits ostensive-inferential communication via open-ended combinatorial productivity.

\section{Speech Control}

'That for which we find words is something already dead in our hearts. There is always a kind of contempt in the act of speaking.' - Friedrich Nietzche (1889) 
220 As Hinzen (2017: p. 306) notes, 'it is in my view timely now to concede that, with language,

221 and apparently inherently and exceptionlessly, goes a form a communication that is as sapiensspecific as language is'. Non-human forms of communication seem able to be classified as adhering to what is often referred to as the 'code model' (Blackburn, 2007); that is, their communication systems involve simple, one-to-one mappings between signs and meanings. There is little decoding required, and everything appears largely unambiguous (Rendall et al., 2009). Current work in the field indicates that primate vocalisations are largely innate and tied to emotional states. Nonhuman primates also do not seem capable of understanding or expressing communicative intent, suggesting a poverty in their ability for mental state attribution. But as Fischer and Price (2017: p. 22) argue, nonhuman primates are nevertheless proficient at integrating multiple information sources, rendering their communicative apparatus 'relatively powerful, despite the lack of higher-order intentionality'. In humans, the ability to exercise voluntary control over speech production depends on neural connections between the primary motor cortex and the nucleus ambiguous, controlling laryngeal motor neurons. Speech production also involves the basal ganglia and cerebellum, while the left anterior insula appears crucial for speech articulation (Wise et al., 1999). In both humans and nonhuman primates, the ventrolateral prefrontal cortex and ventrolateral premotor region, along with the mid-cingulate cortex, coordinate to implement cognitive control over vocalisations - regions which are cytoarchitectonically comparable across humans and nonhuman primates (Kee Loh et al., 2017). In humans, the mid-cingulate cortex and ventrolateral prefrontal and premotor regions are not simply involved in cognitive control over emotion-related vocalisations, but also over acquired vocalisations. The reasons for this may be due to the emergence in humans of a laryngeal representation in the human orofacial motor area, which likely presented humans with a finer degree of motor control over oro-laryngeal motions (Simonyan, 2014). As a result, the mid-cingulate cortex would be able to implement fine oro-laryngeal adjustments, 
something which might explain the ability of humans to flexibly modify vocal behaviour based on contextual cues. Moving beyond these anatomical regions, rostral lateral frontal regions such as Brodmann area (BA) 45 and BA 10 could be involved in higher-order monitoring of speech action choices (Petrides, 2005), and the particular morphology assumed by these regions of the human brain compared to our closest relatives can likely explain in some fashion how these higher cognitive functions are implemented. suggests that it is specifically motor control of the larynx which is human-specific, with the motor neurons for this lying in the nucleus ambiguus within the medulla. Along with the syntactic combinatorial capacities of language (on the syntax-semantics side), human speech (on the sensorimotor side) is also a species-defining trait. I am not aware of any work into the linguistic function or neural dynamics of the nucleus ambiguus of the medulla, but the interactions between the conceptual temporal and parietal systems and these areas during speech would presumably be a prerequisite for a global theory of speech. Kumar et al. (2016) in the macaque brain and thus may form part of the explanation for human speech control. evolved for speech.

267 
In contrast to nonhuman communication systems, human language is rich with ambiguity, for instance in cases of homonymy or polysemy in which a discrete word like bank can refer to a riverbank (John sat by the bank), a financial institution (The bank was sued), a building in which the financial institution is located (The bank is across the street), its employees (The bank went on strike), and so forth (Collins, 2017). While it is typically inadequate, there are a small number of cases in which human language can be analysed as adhering to the code model, as in smiling (Scruton, 2015), frowning and involuntary laughter, with the latter appearing to be an evolutionary homologue to great ape laughter (Bryant and Aktipis, 2014).

Human communication seems to be more complex than the code model, with a substantial amount of contemporary research agreeing that ostensive-inferential communication is a more accurate characterisation. In general, with human language, the semantic meaning of an utterance fails to correspond precisely to what the speaker intends to communicate. This involves the expression and perception of information and communicative intentions (Sperber and Wilson, 1995). For instance, a customer in a restaurant executes a pen writing gesture (providing evidence; ostension) and the waiter fetches the bill (interpreting evidence; inference). This aspect of language almost certainly evolved from natural selection, which above all else produces organisms which act in goal-directed ways (Gardner, 2009), with a major feature of ostensive-inferential communication being the ability to alter and manipulate mental states (see also Moore, 2016 for evidence that some great ape gestures satisfy criteria for ostensive communication).

On the other hand, certain aspects of language are more difficult to square with the logic of natural selection, as mentioned above. Scott-Phillips (2015a, 2015b) claims languagespecific recursion came about because it was needed (that is, because of selectional pressures). Yet, this is not a theory. There currently exists no evidence that language-specific recursion would have adapted as a response to selectional pressures in a continuous evolutionary process 
(Hauser et al., 2014). Scott-Phillips's (2015a: p. 47) central thesis is that 'once ostensiveinferential communication exists, it is used to create the various communicative conventions (semantic, syntactic, phonological, etc.) that we call language'. How the maxims of Relevance Theory could help give birth to phonological representations or long-distance dependencies or the Empty Category Principle is not pursued concretely. Scott-Phillips does not assume that ostensive-inferential communication is the most central aspect of language evolution, nor does he assume that the novelty of language lies in its ability to provide 'new ways to transfer information' (Scott-Phillips 2015a: p. 153). Rather, the emergence of an entirely different linguistic feature allowed humans to combine the operations of two separate cognitive systems often used for communication (producing signals and making inferences), generating new behaviours and forms of communication. This linguistic feature boils down to the capacity to combine elementary representations into hierarchically structured units (Adger, 2019; Pietroski, 2018; Shim, 2018).

Along with the capacity for ostensive-inferential communication comes a need for intersubjectivity. This emerges from an infant's relation with its mother. Humans are unique among primates in that they cradle their infants, most likely because human infants are uniquely vulnerable, with their parents having little body hair to cling onto. The volume of the human infant brain is approximately 25 per cent of the adult brain, whereas the figure is closer to 45 per cent in chimpanzee infants. The human skeletal system is also more vulnerable and is more generally quite poorly developed. A significant effect of this cradling is that infants are in close proximity to their mother's eyes and facial expressions, sharing gazes and emotional expressions (see Konner, 2010 for a comprehensive review). The close temporal correlation between the infant's behaviour and the mother's behaviour is termed dyadic by developmental psychologists, with triadic relations emerging at around 6 months with the addition of objects of mutual interest, facilitating joint attention (a phylogenetically younger capacity). All of these 
factors lay the basis for human-specific levels of attentional and communicative competence; shared with other primates, but well-refined. For instance, without joint attention it would be more difficult for a child to learn the name of a given object, since bear might refer to any feature of an object, any process associated with it, any location the object is placed on, and so forth (Wilkes-Gibbs and Clark, 1992). Yet, as Reboul (2015) discusses, mind-reading relies on metarepresentations generated by a recursive syntax (e.g. Walt believes that Jessie believes that $p$ ), and so it is reasonable to assume that this crucial aspect of human communication (relying as it does on intersubjectivity) was derived from syntax, rather than the other way around. This satisfies a core assumption of minimalist syntactic architecture (initiated in Chomsky, 1995), whereby communication is in fact a tertiary component of language, being a sub-part of externalisation, which is in turn secondary to the primary role of syntactic combinatorics, with syntax being a simple recursive generator which maps objects to a workspace - MERGE (Chomsky et al., 2018) - lacking non-nomological constraints. This radically departs from the more popular assumption that the basic function of language is to communicate information from speaker to hearer (e.g. the Performance-Grammar Correspondence Hypothesis; Hawkins, 2009). Instead, as Jacob (1982: p. 59) summarised, 'the role of language as a communication system between individuals [may have come] about only secondarily'. Mobbs (2015) also reviews how our success in acts of communication significantly varies as a function of personality, education, and other related contingencies: 'If it were communicatively-oriented, this would make the [faculty of language] somewhat anomalous among core domains of cognition, such as vision, memory, motor control, etc., in which the overwhelmingly better part of competence is taken to develop irrespective of anything but major deficiencies in input or other abilities'. There are also a range of unacceptable outputs of syntax - like double-object constructions such as '*I donated the library a book' - that are nevertheless comprehensible; peculiar for a system putatively serving communication. In addition, if the language faculty 
was geared towards communication, one would expect a much more idiosyncratic variation in acceptability levels in grammaticality judgements; a prediction not borne out (Sprouse and Almeida, 2017).

Along with attentional advances, the capacity for mutual trust would also have required certain modifications. Hrdy (2009) argues in a seminal study that a human infant would have needed to share affect not only with its parents but with other caretakers in the community too, given the expanded size of human tribes relative to those of other great apes. Infants which were competent at this generalised affect-sharing would obtain more direct language-relevant data from their caretakers and so would presumably obtain a selectional advantage, not just in the sense that their language faculties would be properly developed, but also in that their mutual trust for their fellow group members would be enhanced. In terms of the evolutionary timeline, Studdert-Kennedy and Terrace (2017: p. 122) note that it is hard to imagine joint attention emerging without the pre-existing foundation of intersubjectivity, nor could one easily conceive of the emergence of an extensive vocabulary without the pre-existing foundation of joint attention; while the dates may be currently hard to pin down, the chain of evolutionary events at least seems somewhat clearer. There is consequently no need to claim with Corballis (2017: p. 571), during a discussion of theory of mind and communicative competence, that 'it is difficult to believe they surfaced in a single step late in the evolution of our species', since we can easily assume that such capacities were largely already in place. Again, this is in line with a core minimalist assumption of saltationism (see Murphy, 2018b for a more detailed timeline which is largely, but not wholly, in accord with the minimalist framework).

While Scott-Phillips (2015a: p. 46) maintains that 'nothing that looks even remotely like language can emerge prior to the evolution of ostensive-inferential communication', what likely happened was that the ability to generate phrase structure emerged, which paired ostensive and inferential cognitive systems, which in turn helped the phrase structure- 
generating procedure reach into broader conceptual territory through communication with conspecifics, generating an ever-expanding list of representational combinations (possibly through reciprocal causation; Lewontin, 1983; Walsh, 2015). This model of paired, interfacing systems is well within the scope of minimalist assumptions, and is indeed necessitated by them.

\section{Implementational Concerns}

Additional barriers are also faced by those wishing to develop a communicative model of language. For instance, it is difficult to explore the neurobiological basis of communication because this notion, in connection to human language, has not been sufficiently decomposed into its computational primitives. On the other hand, syntactic, semantic and phonological computations have been decomposed to a sufficiently generic level, permitting a range of brainlanguage linking hypotheses (e.g. Grimaldi 2018; Murphy 2015, 2016a, 2016a, 2016c, 2018a; Murphy and Benítez-Burraco, 2017). Evolutionary theories are increasingly being grounded in our understanding of the brain (Murphy and Benítez-Burraco, 2018), and so communicative theories of language evolution currently face this considerably great (and little-acknowledged) obstacle. Language becomes open for evolutionary study once we acknowledge that it is not 'embedded' somehow in a speech community but is rather part of a speaker's mental life, and therefore part of their physical existence. Figure 1 depicts a recent model for the neurobiological basis of minimalist syntax - nothing remotely similar has been developed for communicative models of language. 


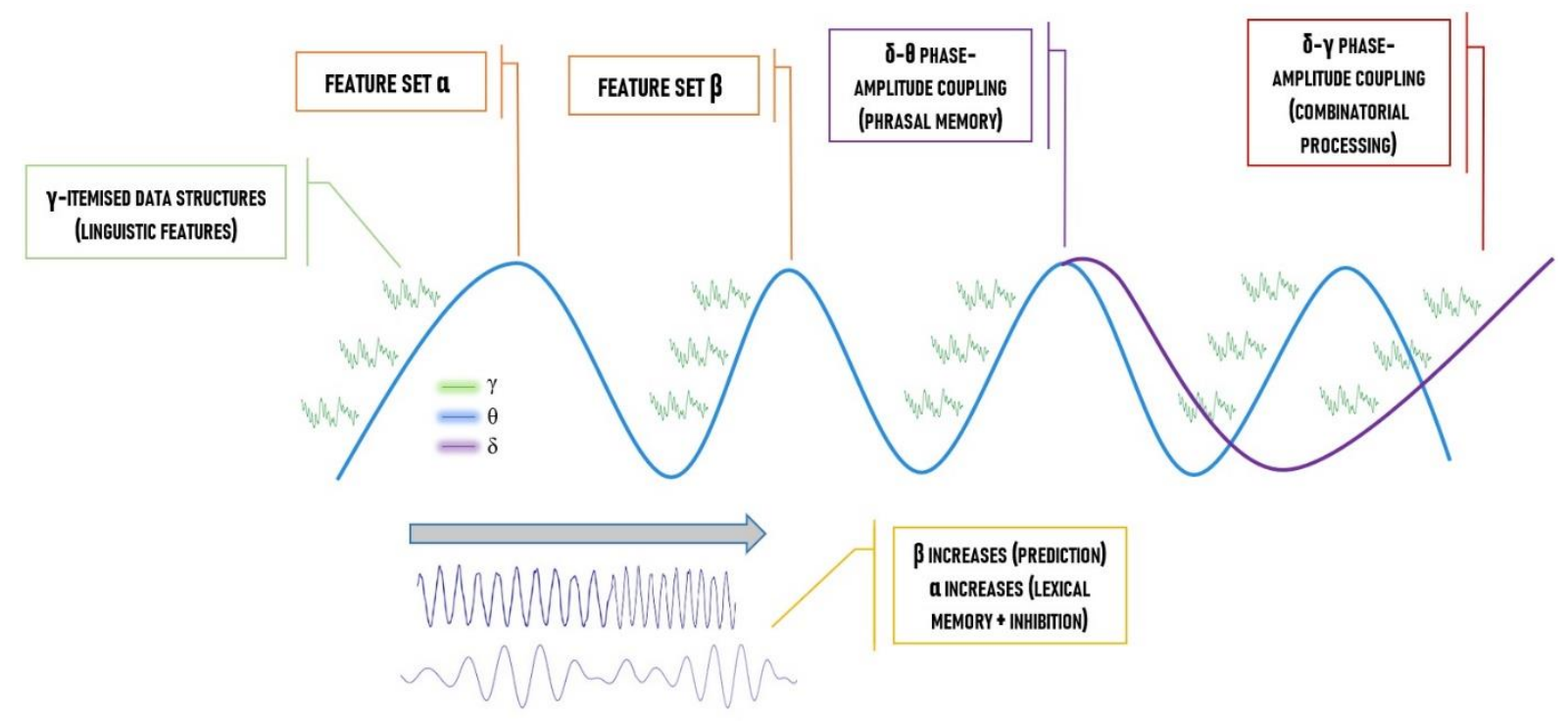

Figure 1. A neural code for language, representing the various oscillatory cross-frequency coupling interactions proposed to implement hierarchical phrase structure building (depicting the model in Murphy, 2018a).

This internalist focus on the mental faculty of language (Berwick, 2017) is in stark contrast to the externalist focus on the output of language, such as speech and communication. Fisher (2016) and Fisher and Vernes (2015), along with many others, have explored in some detail the genetics of speech and communication, but it is unclear whether this relates to language evolution if language is understood in the computational/representational terms of minimalism. Distinguishing speech from language (and from communication) is an essential first step in exploring the biological basis of higher cognition.

\section{Conclusion}

The currently available evidence grants greater support to the minimalist conception of language as being primarily a system contributing to higher cognition than it does to the communicative view of language use and evolution. Overall, it not only undermines the complexity of human language to hold that its primary evolutionary function is 
communication; given the complexity of nonhuman cognition reviewed here, focusing on the communication systems of animals - as opposed to their conceptual capacities - also undermines them.

\section{References}

Aboitiz, F. (2017). A Brain for Speech: A View from Evolutionary Neuroanatomy. London: Palgrave Macmillan.

Ackema, P., \& Neeleman, A. (2002). Effects of short term storage in processing rightward movement. Noteboom, S., Weerman, F., \& Wijnen, F. (Eds). Storage and Computation in the Language Faculty. Dordrecht: Kluwer. 219-256.

Adger, D. (2019). Syntax Unlimited: The Science Behind Our Most Creative Power. Oxford: Oxford University Press.

Amundson, R. (2006). EvoDevo as cognitive psychology. Biological Theory 1(1): 10-11.

Anderson, S.R. (2004). Doctor Dolittle's Delusion: Animals and the Uniqueness of Language. London: Yale University Press.

Arbib, M. (2012). How the Brain got Language: The Mirror System Hypothesis. Oxford: Oxford University Press.

Aust, U., Range, F., Steurer, M., \& Huber, L. (2008). Inferential reasoning by exclusion in pigeons, dogs, and humans. Animal Cognition 11(4): 587-597.

Berwick, R.C. (2017). A feeling for the phenotype. In McGilvray, J. (Ed). The Cambridge Companion to Chomsky. 2nd ed. Cambridge: Cambridge University Press. 87-109.

Bickerton, D. (2009). Adam's Tongue. New York: Hill and Wang.

Blackburn, P. (2007). The Code Model of Language: A Powerful Metaphor in Linguistic Metatheory. SIL International. 
Boeckx, C. (2003). Islands and Chains: Resumption as Stranding. Amsterdam: John Benjamins.

Bolhuis, J.J., Tattersall, I., Chomsky, N., \& Berwick, R.C. (2014). How could language have evolved? PLoS ONE 12: e1001934.

Bouchard, D. (2013). The Nature and Origin of Language. Oxford: Oxford University Press.

Bryant, G.A., \& Aktipis, A. (2014). The animal nature of spontaneous human laughter. Evolution and Human Behavior 35(4): 327-335.

Burge, T. (1979). Individualism and the mental. Midwest Studies in Philosophy 4: 73-121.

Chomsky, N. (1995). The Minimalist Program. Cambridge, MA: MIT Press.

Chomsky, N. (2000). New Horizons in the Study of Language and Mind. Cambridge, MA: MIT Press.

Chomsky, N. (2001). Beyond explanatory adequacy. MIT Occasional Papers in Linguistics 20: $1-28$

Chomsky, N. (2018). Mentality beyond consciousness. Caruso, G. (Ed). Ted Honderich on Consciousness, Determinism, and Humanity. London: Palgrave Macmillan. 33-46.

Chomsky, N., Gallego, Á.J., \& Ott, D. (2018). Generative grammar and the faculty of language: insights, questions, and challenges. Gallego, Á.J., \& Ott, D. (Eds). Generative Syntax: Questions, Crossroads, and Challenges. Special issue of Catalan Journal of Linguistics.

Collins, J. (2017). The copredication argument. Inquiry 60(7): 675-702.

Corballis, M. (2017). Leaps of faith: a reply to Everaert et al. Trends in Cognitive Sciences 21(8): 571-572.

Corp, N., \& Byrne, R.W. (2002). Ontogeny of manual skill in wild chimpanzees: evidence 455 from feeding on the fruit of Saba Florida. Behavior 139: 137-168.

Dor, D. (2017). The role of the lie in the evolution of human language. Language Sciences 63: 44-59. 
Engesser, S., Ridley, A.R., \& Townsend, S.W. (2016). Meaningful call combinations and compositional processing in the southern pied babbler. PNAS 113(21): 5976-5981.

Fischer, J., \& Price, T. (2017) Meaning, intention, and inference in primate vocal communication. Neuroscience and Biobehavioral Reviews 82: 22-31.

Fisher, S.E. (2016). A molecular genetic perspective on speech and language. In Hickok, G., \& Small, S. (Eds). Neurobiology of Language. Amsterdam: Elsevier. 13-24.

Fisher, S.E., \& Vernes, S. (2015). Genetics and the language sciences. Annual Review of Linguistics 1: 289-310.

Fitch, W.T. (2018). The biology and evolution of speech: a comparative analysis. Annual Review of Linguistics 4: 255-279.

Fodor, J.A., \& Pylyshyn, Z.W. (2015). Minds Without Meaning: An Essay on the Content of Concepts. Cambridge, MA: MIT Press.

Gardner, A. (2009). Adaptation as organism design. Biology Letters 5(6): 861-864.

Grimaldi, M. (2018), The phonetics-phonology relationship in the neurobiology of language. Petrosino, R., Cerrone, P. \& van der Hulst, H. (Eds). From Sounds to Structures: Beyond the Veil of Maya. Berlin: De Gruyter. 65-103.

Hauser, M., Yang, C., Berwick, R. C., Tattersall, I., Ryan, M. J., Watumull, J., Chomsky, N., \& Lewontin, R. C. (2014). The mystery of language evolution. Frontiers in Psychology 5: 401.

Hauser, M., \& Watumull, J. (2017). The Universal Generative Faculty: the source of our expressive power in language, mathematics, morality, and music. Journal of Neurolinguistics 43(B): 78-94.

Hawkins, J. (2009). Language universals and the Performance-Grammar Correspondence Hypothesis. Christiansen, M., Collins, C., \& Edelman, S. (Eds). Language Universals. Oxford: Oxford University Press. 54-78. 
Herman, L.M., Uyeyama, R.K., \& Pack, A.A. (2008). Bottlenose dolphins understand relationships between concepts. Behavioral and Brain Sciences 31(2): 139-140.

Hinzen, W. (2006). Mind Design and Minimal Syntax. Oxford: Oxford University Press.

Hinzen, W. (2007). An Essay on Names and Truth. Oxford: Oxford University Press.

Hinzen, W. (2017). What language is. Theoretical Linguistics 43(3-4): 297-317.

Hobaiter, C., \& Byrne, R.W. (2017). What is a gesture? A meaning-based approach to defining gestural repertoires. Neuroscience and Biobehavioral Reviews 82: 3-12.

Hornstein, N. (1984). Logic as Grammar: An Approach to Meaning in Natural Language. Cambridge, MA: MIT Press.

Hrdy, S.B. (2009). Mothers and Others: The Evolutionary Origins of Mutual Understanding. Cambridge, MA: Belknap Press of Harvard University Press.

Huxley, A. (1931). Sermons in cats. Music at Night and Other Essays. New York: Doubleday, Doran \& Co.

Jackendoff, R. (1990). Semantic Structures. Cambridge, MA: MIT Press.

Kalashnikova, M., Carignan, C., \& Burnham, D. (2017). The origins of babytalk: smiling, teaching or social convergence? Royal Society Open Science 4: 170306.

Kayne, R.S. (1994). The Antisymmetry of Syntax. Cambridge, MA: MIT Press.

Kee Loh, K., Petrides, M., Hopkins, W.D., Procyk, E., \& Amiez, C. (2017). Cognitive control of vocalizations in the primate ventrolateral-dorsomedial frontal (VLF-DMF) brain network. Neuroscience and Biobehavioral Reviews 82: 32-44.

Konner, M. (2010). The Evolution of Childhood: Relationships, Emotion, Mind. London: The Belknap Press of Harvard University Press.

Kumar, V., Croxson, P.L., \& Simonyan, K. (2016). Structural organization of the laryngeal motor cortical network and its implication for evolution of speech production. Journal of Neuroscience 36: 4170-4181. 
508

509

510

511

512

513

514

515

516

517

518

519

520

521

522

523

524

525

526

527

528

529

530

531

Lewontin, R.C. (1983). Gene, organism, and environment. Bendall, D.S. (Ed). Evolution from Molecules to Men. Cambridge: Cambridge University Press. 273-285.

McGhee, G. (1998). Theoretical Morphology. Columbia University Press.

Meguerditchian, A., Vuillemin, A., \& Pruetz, J.D. (2017). Identifying the ape beat in the wild: rhythmic individual signatures from the sounds of manual fruit cracking in Fongoli chimpanzees. Ms. Aix-Marseille Université.

Meltzoff, A.N., \& Moore, M.K. (1997). Explaining facial imitation: a theoretical model. Early Development and Parenting 6: 179-192.

Mobbs, I.J. (2015). Minimalism and the Design of the Language Faculty. PhD dissertation. University of Cambridge.

Moore, R. (2016). Meaning and ostension in great ape gestural communication. Animal Cognition 19(1): 223-231.

Murphy, E. (2015). The brain dynamics of linguistic computation. Frontiers in Psychology 6: 1515.

Murphy, E. (2016a). A theta-gamma neural code for feature set composition with phaseentrained delta nestings. UCL Working Papers in Linguistics 28: 1-23.

Murphy, E. (2016b). Evolutionary monkey oscillomics: Generating linking hypotheses from preserved brain rhythms. Theoretical Linguistics 42(1-2): 117-137.

Murphy, E. (2016c). The human oscillome and its explanatory potential. Biolinguistics 10: 620.

Murphy, E. (2018a). Interfaces (travelling oscillations) + recursion (delta-theta code) $=$ language. Luef, E., \& Manuela, M. (Eds). The Talking Species: Perspectives on the Evolutionary, Neuronal and Cultural Foundations of Language. Graz: Unipress Graz Verlag. 251-269. 
Murphy, E. (2018b). No country for Oldowan men: self-domestication and cranial globularity as factors in language evolution. UCL Working Papers in Linguistics 30: 35-56.

Murphy, E., \& Benítez-Burraco, A. (2017). Language deficits in schizophrenia and autism as related oscillatory connectomopathies: an evolutionary account. Neuroscience \& Biobehavioral Reviews 83: 742-764.

Murphy, E., \& Benítez-Burraco, A. (2018). Paleo-oscillomics: inferring aspects of Neanderthal language abilities from gene regulation of neural oscillations. Journal of Anthropological Sciences 96: 111-124.

Nietzche, F. (1998/1889). Twilight of the Idols. Large, D. (trans.). Oxford: Oxford University Press.

Owren, M.J., Amoss, R.T., \& Rendall, D. (2011). Two organizing principles of vocal product2ion: implications for nonhuman and human primates. American Journal of Primatology 73(6): 530-544.

Owren, M.J., Rendall, D., \& Ryan, M.J. (2010). Redefining animal signaling: influence versus information in communication. Biology \& Philosophy 25: 755-780.

Rendall, D., Owren, M.J., \& Ryan, M.J. (2009). What do animal signals mean? Animal Behaviour 78: 233-240.

Patterson, F.G., \& Linden, E. (1981). The Education of Koko. New York: Holt, Rinehart and Winston.

Paz-y-Miño, G., Bond, A.B., Kamil, A.C., \& Balda, R.P. (2004). Pinyon jays use transitive inference to predict social dominance. Nature 430: 778-781.

Petrides, M. (2005). Lateral prefrontal cortex: architectonic and functional organization. Philosophical Transactions of the Royal Society B 360: 781-795.

Pietroski, P. (2018). Conjoining Meanings: Semantics Without Truth Values. Oxford: Oxford University Press. 
Pietroski, P., \& Crain, S. (2005). Innate ideas. McGilvray, J. (Ed). The Cambridge Companion to Chomsky. Cambridge: Cambridge University Press.

Putnam, H. (1975). The meaning of 'meaning'. Minnesota Studies in the Philosophy of Science 7: 131-193.

Reboul, A.C. (2015). Why language really is not a communication system: a cognitive view of language evolution. Frontiers in Psychology 6: 1434.

Scott-Phillips, T.C. (2015a). Speaking Our Minds: Why Human Communication is Different, and How Language Evolved to Make It Special. New York: Palgrave Macmillan.

Scott-Phillips, T.C. (2015b). Nonhuman primate communication, pragmatics, and the origins of language. Current Anthropology 56(1): 56-80.

Scruton, R. (2015). Smiles from reason flow. Lecture delivered at the Alpine Fellowship, Venice.

Shettleworth, S.J. (2009). Cognition, Evolution, and Behavior. Oxford: Oxford University Press.

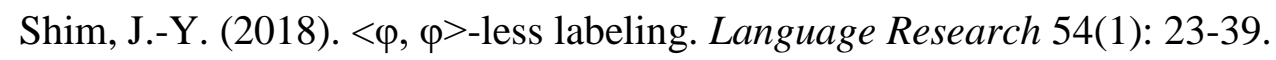

Simonyan, K. (2014). The laryngeal motor cortex: its organization and connectivity. Current Opinion in Neurobiology 28: 15-21.

Sperber, D., \& Wilson, D. (1995). Relevance: Communication and Cognition. 2nd ed. Oxford: Blackwell.

Sprouse, J., \& Almeida, D. (2017). Setting the empirical record straight: acceptability judgments appear to be reliable, robust, and replicable. Behavioral and Brain Sciences 40: e311.

Steels, L. (1995). A self-organizing spatial vocabulary. Artificial Life 2: 319-332.

Studdert-Kennedy, M., \& Terrace, H. (2017). In the beginning: a review of Robert C. Berwick and Noam Chomsky's Why Only Us. Journal of Language Evolution 2(2): 114-125. 
582 Terrace, H.S. (2005). Metacognition and the evolution of language. In Terrace, H.S., \& 583 Metcalfe, J. (Eds). The Missing Link in Cognition: Origins of Self-Reflective Consciousness. 584 Oxford: Oxford University Press. 84-115.

585 Walsh, D.M. (2015). Organisms, Agency, and Evolution. Cambridge: Cambridge University $586 \quad$ Press.

587 Wijnen, F. (2013). Acquisition of linguistic categories: cross-domain convergences. In 588 Bolhuis, J.J., \& Everaert, M. (Eds). Birdsong, Speech, and Language: Exploring the 589 Evolution of Mind and Brain. Cambridge, MA: MIT Press. 157-177.

590 Wilkes-Gibbs, D., \& Clark, H.H. (1992). Coordinating beliefs in conversation. Journal of $591 \quad$ Memory \& Language 31: 183-194.

592 Wise, R.J.S., Greene, J., Büchel, C., \& Scott, S.K. (1999). Brain systems for word perception $593 \quad$ and articulation. Lancet 353: 1057-1061.

594 Zuberbühler, K. (2012). Cooperative breeding and the evolution of vocal flexibility. In 595 Tallerman, M., \& Gibson, K.R. (Eds). The Oxford Handbook of Language Evolution. 596 Oxford: Oxford University Press. 71-81. 